\title{
THE DIVERSITY OF BREADFRUIT PLANTS (ARTOCARPUS ALTILIS) BASED ON MORPHOLOGICAL CHARACTERS
}

\author{
Helna Estalansa'), Endang Yuniastuti ${ }^{2)}$, Sri Hartati ${ }^{3)}$ \\ 1) Student of Agrotechnology Major Agriculture Faculty UNS Surakarta \\ 2) Lecturer Staff of Agrotechnology Major Agriculture Faculty UNS Surakarta \\ Author Contact: yuniastutisibuea@staff.uns.ac.id
}

\begin{abstract}
Breadfruit (Artocarpus altilis) is a plant common are all part of it can be used by humans. The research aims to determine the character of morphological breadfruit and knowing the characterization of morphological breadfruit in Yogyakarta. This research was carried out in June to October 2017 in Sleman Regency (Cangkringan, Ngemplak, Ngaglik), Gunung Kidul (Patuk, Nglipar, Gedangsari), and Bantul (Bantul, Pajangan, Imogiri) in Yogyakarta. Variables are observations include the environmental research and morphology of (trees, leaves, flowers, and fruits). The data of the morphology are analyzed by NTSYS program. The results showed that the breadfruit trees has a plant height 16,7-17,9 m, the diameter of crown 6,1-8,8 m, shape of crown of the pyramidal, broadly pyramidal, elliptical, irregular, the patterns of branching of erect, opposite, and irregular. The length of leaf $42,2-$ $78,6 \mathrm{~cm}$, width of leaf $30,2-59,2 \mathrm{~cm}$, shape of leaf ovate, and leaf colour dark green. The length of male flowers 9,0-13,4 cm, shape of female flowers globose, shape of male flowers ellipsoid, the colour of female flowers light green, the colour of male flowers light green when young, and brown when old. The length of fruit 12,2-19,0 cm, diameter of fruit 12,8-16,4 cm, weight of fruit $0,7-1,7 \mathrm{~kg}$, shape of fruit sperical and oblong, fruit skin colour greenish yellow, fruit flesh colour white and light yellow. The diversity of morphology of the breadfruit plants ranging from 3$30 \%$.
\end{abstract}

Keywords: Characterization, Similarity, Dendrogram

\section{AGROTECHNOLOGY RESEARCH JOURNAL}

Estalansa H, Yuniastuti E, Hartati S. 2018. Keragaman tanaman sukun (Artocarpus altilis) berdasarkan karakter morfologi. Agrotech Res J 2(2): 80-85.

Estalansa H, Yuniastuti E, Hartati S. 2018. The diversity of breadfruit plants (Artocarpus altilis) based on morphological characters. Agrotech Res J 2(2): 80-85.

\section{PENDAHULUAN}

Sukun merupakan tanaman serbaguna yang dapat dimanfaatkan oleh manusia (Purwantoyo 2007). Mulai dari buahnya sebagai bahan pangan, daunnya untuk mengatasi berbagai penyakit, bunganya dapat dijadikan obat pengusir nyamuk, dan batangnya dimanfaatkan sebagai bahan bangunan (Supriyati 2010). Tanaman sukun menghasilkan buah yang memiliki karbohidrat dan kandungan gizi tinggi, sehingga potensial sebagai bahan makanan pokok alternatif pengganti beras (Adinugraha dan Kartikawati 2012).

Penyebaran tanaman sukun di Indonesia sangat luas mulai dari Aceh sampai Papua (Rukmana 2007). Sukun sangat cocok tumbuh di daerah panas dan beriklim tropis (Sikarwar et al. 2014). Sukun tergolong mudah dibudidayakan secara berkelanjutan dengan sedikit input pertanian (Jones et al. 2011). Penanaman pada lahan terbuka tidak ternaungi akan membantu pertumbuhan dan produksi sukun. Buah sukun lokal rata-rata memiliki berat $1-2 \mathrm{~kg} / \mathrm{buah}$ dan jumlah buah sekali panen \pm 50 buah/pohon (Djafaar 2004).

$\mathrm{Di}$ Indonesia keberadaan sukun ini masih bersifat sporadis dan tidak dibudidayakan. Permasalahan yang sering muncul yaitu sukun tumbuh di tepian hutan, sawah dan sungai serta ditanam tanpa ada tujuan komersil di kebun atau pekarangan rumah, padahal kondisi iklim tergolong cocok untuk membudidayakan sukun secara intensif (Hendalastuti dan Rojidin 2006).

*Fak. Pertanian UNS Surakarta

Jl. Ir. Sutami 36 A Surakarta
Pemanfaatan tanaman sukun terutama buahnya masih belum optimal dan sering diabaikan (Akanbi et al. 2009).

\section{METODE PENELITIAN}

Penelitian dilaksanakan pada bulan Juni sampai Oktober 2017 di Kabupaten Sleman (Kecamatan Cangkringan/S1, Ngemplak/S2, Ngaglik/S3), Kabupaten Gunung Kidul (Kecamatan Patuk/S4, Nglipar/S5, Gedangsari/S6), dan Kabupaten Bantul (Kecamatan Bantul/S7, Pajangan/S8, Imogiri/S9) di Yogyakarta. Setiap kecamatan diambil satu pohon sukun. Alat yang digunakan yaitu deskriptor tanaman IBPGRI (International Board Plant Genetic Resources Institute), GPS, klinometer, meteran, dan timbangan.

Penelitian menggunakan metode eksploratif. Sampel dipilih secara sengaja dengan kriteria: sudah dewasa, memiliki umur lebih dari 10 tahun, sudah pernah berbuah, memiliki bagian tanaman yang dibutuhkan, dan berdasarkan rekomendasi masyarakat sekitar. Jenis data yaitu data primer berupa morfologi tanaman yang diamati langsung di lapangan dan data sekunder berupa ketinggian tempat dari permukaan air laut, letak lintang, letak bujur, suhu, kelembaban, dan data curah hujan.

Teknik pengumpulan data meliputi observasi di lapangan, wawancara responden, dokumentasi, dan studi pustaka. Hasil data yang diperoleh di skoring mengikuti deskriptor dari IBPGRI yang telah dimodifikasi untuk masing-masing variabel (Alercia 
2011, IPGRI 2000, dan Bioversity 2007). Variabel pengamatan meliputi:

1. Pengamatan kondisi lingkungan penelitian

2. Pengamatan morfologi tanaman

a. Morfologi pohon: tinggi tanaman, lingkar batang, diameter tajuk, bentuk tajuk, pola percabangan, jumlah cabang utama, dan arah pertumbuhan.

b. Morfologi daun: panjang daun, lebar daun, panjang tangkai daun, bentuk daun, bentuk pangkal daun, bentuk ujung daun, susunan tulang daun, warna daun, dan kilap permukaan daun.

c. Morfologi bunga: panjang bunga jantan, diameter bunga jantan, bentuk bunga betina, bentuk bunga jantan, warna bunga betina, dan warna bunga jantan.

d. Morfologi buah: panjang buah, diameter buah, panjang tangkai buah, berat buah, bentuk buah, bentuk pangkal buah, bentuk ujung buah, warna kulit buah, warna daging buah, dan banyaknya buah per pohon.

Data hasil pengamatan dianalisis menggunakan program Numerical Taxonomy and Multivariate Analys System (NTSYS) versi 2.02i. Data dibuat dalam bentuk skor, kemudian diubah menjadi data biner (0-1) untuk dianalisis menggunakan matriks similaritas (SimQual) dengan koefisien kemiripan DICE. Pengelompokkan dilakukan menggunakan metode Unweighted Pair Group Method Arithmatic Average (UPGMA) yang dihitung melalui SAHN kemudian disatukan dalam bentuk dendrogram berdasarkan kemiripan.

\section{HASIL DAN PEMBAHASAN}

\section{Kondisi umum penelitian}

Lokasi penelitian terletak di Kabupaten Sleman, Gunung Kidul, dan Bantul. Lokasi penelitian tersebut memiliki curah hujan rata-rata 1460-3179 mm/tahun, suhu harian rata-rata $22-31^{\circ} \mathrm{C}$ dengan kelembaban $60-$ $90 \%$, memiliki jenis tanah regosol dan latosol. Menurut Azmi et al. 2015, regosol adalah tanah muda yang gembur, bertekstur pasir, dan berasal dari bahan induk material vulkanik. Apriani et al. (2015) menyatakan bahwa tanah latosol bertekstur lempung, struktur remah hingga gumpal, dan berwarna cokelat kemerahan.

1. Kabupaten Sleman

Lokasi pertama berada di Kec. Cangkringan dengan koordinat $7^{\circ} 40^{\prime} 43,2^{\prime \prime}$ LS- $110^{\circ} 28^{\prime} 04,6^{\prime \prime}$ BT pada ketinggian $332 \mathrm{~m}$ dpl. Lokasi kedua berada di Kec. Ngemplak dengan koordinat $7^{\circ} 41^{\prime}$, 48,1" LS$110^{\circ} 27^{\prime} 25,3^{\prime \prime}$ BT pada ketinggian $289 \mathrm{~m}$ dpl. Lokasi ketiga berada di Kec. Ngaglik dengan koordinat $7^{\circ}$ 41' 56,7" LS-110 $25^{\prime}$ '30,6" BT pada ketinggian 290 $\mathrm{m}$ dpl.

2. Kabupaten Gunung Kidul

Lokasi pertama berada di Kec. Patuk dengan koordinat $7^{\circ} 51^{\prime} 51,0^{\prime \prime}$ LS-110 $30^{\circ} 30,8^{\prime \prime}$ BT pada ketinggian $185 \mathrm{~m}$ dpl. Lokasi kedua berada di Kec. Nglipar dengan koordinat $7^{\circ} 52^{\prime} 57,4^{\prime \prime}$ LS- $110^{\circ} 34^{\prime}$ 02,8 " BT pada ketinggian $184 \mathrm{~m}$ dpl. Lokasi ketiga berada di Kec. Gedangsari dengan koordinat $7^{\circ} 52^{\prime}$ 29,4" LS- $110^{\circ} 34^{\prime} 42,8^{\prime \prime}$ BT pada ketinggian $180 \mathrm{~m}$ dpl.
3. Kabupaten Bantul

Lokasi pertama berada di Kec. Bantul dengan koordinat $7^{\circ} 54^{\prime} 14,2^{\prime \prime}$ LS-110 $10^{\circ}$ '17,4" BT pada ketinggian $49 \mathrm{~m}$ dpl. Lokasi kedua berada di Kec. Pajangan dengan koordinat $7^{\circ} 52^{\prime}$ 40,9' LS-110 19' 06,0" BT pada ketinggian $67 \mathrm{~m}$ dpl. Lokasi ketiga berada di Kec. Imogiri dengan koordinat $7^{\circ}$ 55' 14,6" LS-110 $22^{\circ} 33,7^{\prime \prime}$ BT pada ketinggian $55 \mathrm{~m}$ dpl.

\section{Morfologi pohon}

Tinggi tanaman sukun yang diamati rata-rata memiliki tinggi $\pm 17 \mathrm{~m}$. Tinggi tanaman sukun yang tertinggi yaitu $17,90 \mathrm{~m}$ pada $\mathrm{S} 1$, dan yang terendah $16,79 \mathrm{~m}$ pada S5. Menurut Moles et al. (2009), tinggi tanaman penentu utama kemampuan tanaman untuk bersaing dalam mendapatkan cahaya. Lingkar batang sukun terbesar yaitu $168 \mathrm{~cm}$ pada $S 1$, dan yang terkecil $108 \mathrm{~cm}$ pada S3. Mansyurdin et al. (2016) menyatakan bahwa pohon yang memiliki umur lebih tua akan memiliki lingkar batang yang lebih besar. Sampel yang diamati memiliki umur antara 11-30 tahun. Diamater tajuk terbesar yaitu $8,86 \mathrm{~m}$ pada $\mathrm{S} 1$, dan yang terkecil 6,14 m pada S9. Menurut Mawazin dan Suhaendi (2008), semakin lebar jarak antar tanaman maka diameter tajuknya makin besar, sedangkan semakin rapat jarak antar tanaman maka diameternya semakin kecil. Bentuk tajuk tanaman sukun disajikan pada Gambar 1.

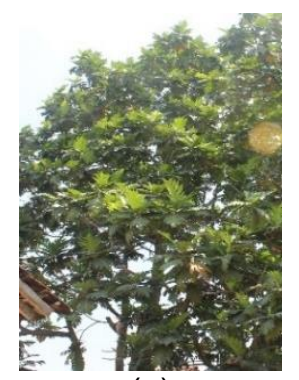

(a)

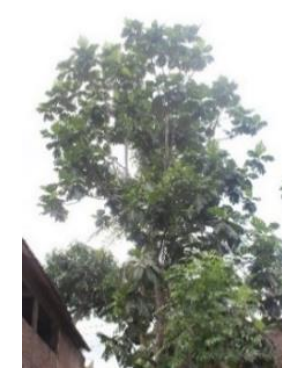

(c)

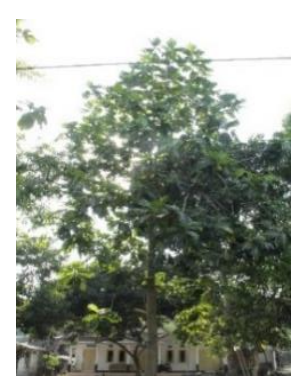

(b)

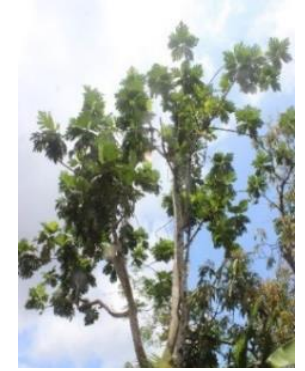

(d)
Gambar 1 Bentuk tajuk: (a) piramida, (b) piramida luas, (c) bulat panjang, dan (d) tidak teratur

Tanaman sukun yang memiliki bentuk tajuk piramida terdapat pada $\mathrm{S} 8$, bentuk tajuk piramida luas terdapat pada S1, S2, S3, S7, bentuk tajuk bulat panjang terdapat pada S5 dan S9, bentuk tajuk tidak teratur terdapat pada S4 dan S6. Pola percabangan tanaman sukun yang termasuk tegak terdapat pada S4, pola percabangan berlawanan terdapat pada S1, S2, S3, S5, S7, S8, S9, dan pola percabangan tidak teratur terdapat pada S6. Jumlah cabang utama paling banyak pada $S 1$ yaitu 18 cabang, dan yang paling sedikit pada S4 yaitu 2 cabang. Semua sampel memiliki arah 
pertumbuhan yang sama yaitu condong ke atas, kecuali S4 yang memiliki arah pertumbuhan tegak.

\section{Morfologi daun}

Daun sukun terpanjang yaitu $78,6 \mathrm{~cm}$ pada $\mathrm{S} 1$, dan yang terpendek $42,2 \mathrm{~cm}$ pada S4. Deivanai dan Bhore (2010) menyatakan bahwa daun sukun memiliki berbagai ukuran panjang dalam satu pohon yaitu mulai dari $22 \mathrm{~cm}$ hingga $90 \mathrm{~cm}$. Lebar daun sukun terbesar yaitu $59,2 \mathrm{~cm}$ pada $S 1$, dan yang terkecil yaitu $30,2 \mathrm{~cm}$ pada S4. Tangkai daun sukun terpanjang yaitu $8,2 \mathrm{~cm}$ pada $S 2$, dan yang terpendek yaitu $5,0 \mathrm{~cm}$ pada $\mathrm{S} 4$, S6, dan S8. Bentuk daun sukun disajikan pada Gambar 2.

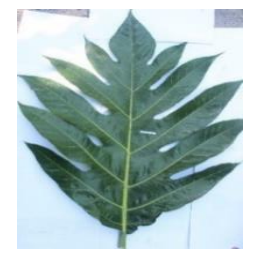

(a)

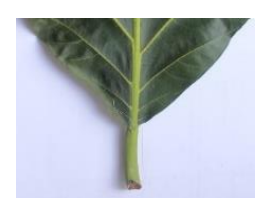

(b)

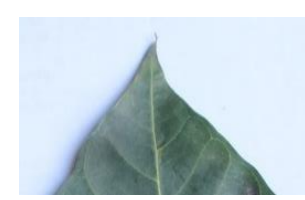

(c)
Gambar 2 Bentuk daun: (a) bulat telur, (b) pangkal membaji, dan (c) ujung meruncing

Daun sukun berbentuk bulat telur dengan pangkal membaji seperti segitiga sama kaki membalik (Yang et al. 2015), ujung meruncing, dan bertulang daun menyirip. Elevitch (2006) menyatakan bahwa daun sukun bagian atas memiliki warna hijau tua dengan tulang daun yang berwarna hijau atau hijau kekuningan, sedangkan bagian bawah daun sukun berwarna hijau kusam. Ragone (1997) menyatakan bahwa bagian atas daun sukun licin, mengkilap dan halus, sedangkan untuk bagian bawah daun memiliki rambut-rambut halus dan bertekstur kasar.

\section{Morfologi bunga}

Bunga jantan pada sukun yang terpanjang yaitu $13,4 \mathrm{~cm}$ pada $S 3$, dan terpendek yaitu $9,0 \mathrm{~cm}$ pada $S 8$. Menurut Harmanto (2012), panjang bunga jantan pada sukun dapat mencapai hingga $15 \mathrm{~cm}$. Sukun termasuk tanaman berumah satu dengan kelamin tunggal, karena bunga jantan dan bunga betinanya terpisah tetapi masih dalam satu tanaman. Diameter bunga jantan sukun terbesar yaitu $3,0 \mathrm{~cm}$ pada $\mathrm{S} 3$, dan yang terkecil yaitu $1,7 \mathrm{~cm}$ pada $\mathrm{S} 8$. Bunga sukun keluar dari ketiak daun pada ujung cabang. Bentuk bunga sukun disajikan pada Gambar 3.

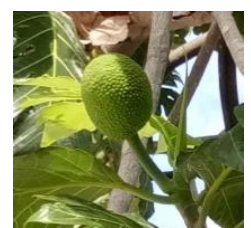

(a)

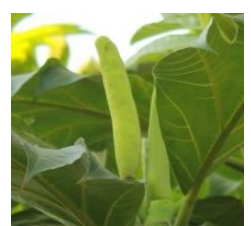

(b)
Gambar 3 (a) bunga betina dan (b) bunga jantan

Bentuk bunga betina sukun berada di skor 1 yaitu bulat. Menurut Sunarjono (2008), bunga betina sukun berbentuk bulat dengan tangkai yang pendek dan biasa disebut dengan babal. Bentuk bunga jantan sukun berada di skor 4 yaitu jorong. Harmanto (2012) menyatakan bahwa bunga jantan berbentuk seperti gada atau tongkat panjang yang biasa disebut dengan ontel. Bunga betina memiliki warna yang berada di skor 1 yaitu hijau muda. Rehatta dan Kesaulya (2010) menyatakan bahwa bunga betina pada sukun bertangkai pendek, kaku, dan berwarna hijau. Bunga jantan sukun memiliki warna yaitu hijau muda ketika muda, kuning tua ketika masak, dan cokelat ketika tua (Nayeem dan Sushmita 2013).

\section{Morfologi buah}

Buah sukun terpanjang yaitu $19,0 \mathrm{~cm}$ pada $\mathrm{S} 1$, dan yang terpendek yaitu $12,2 \mathrm{~cm}$ pada S8. Nochera dan Ragone (2016) menyatakan bahwa buah sukun umumnya memiliki panjang 9-20 cm. Diameter buah sukun terbesar yaitu $16,4 \mathrm{~cm}$ pada $\mathrm{S} 7$, dan yang terkecil yaitu $12,8 \mathrm{~cm}$ pada S8. Tangkai buah sukun terpanjang yaitu $8,2 \mathrm{~cm}$ pada $S 1$, dan yang terpendek yaitu $5,8 \mathrm{~cm}$ pada $\mathrm{S} 4$. Berat buah sukun terbesar yaitu $1,77 \mathrm{~kg}$ pada $\mathrm{S} 1$, dan terkecil yaitu $0,79 \mathrm{~kg}$ pada $\mathrm{S} 8$. Bentuk dan warna buah sukun disajikan pada Gambar 4.

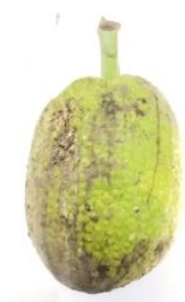

(a)

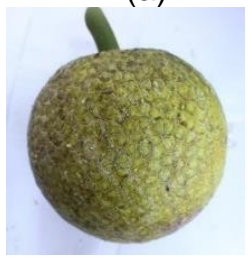

(d)

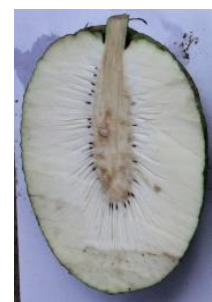

(b)

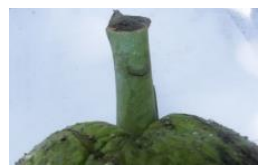

(e)

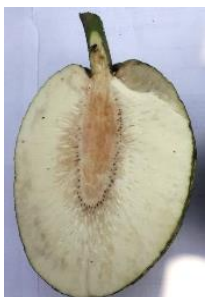

(c)

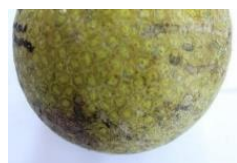

(f)
Gambar 4 (a) bentuk buah bujur, (b) warna daging putih, (c) warna daging kuning muda, (d) bentuk buah bulat, (e) bentuk pangkal menjorok, dan (f) bentuk ujung cembung

Bentuk buah sukun yang diamati ada dua yaitu bujur dan bulat. Buah sukun pada S1, S2, S3, S4, S5, dan S6 memilki bentuk buah bujur, sedangkan pada S7, S8, dan S9 memiliki bentuk buah bulat. Bentuk pangkal buah berada di skor 1 yaitu menjorok. Bentuk ujung buah berada di skor 2 yaitu cembung. Warna kulit buah berada di skor 2 yaitu hijau kekuningan. Menurut Suprapti (2006), kulit buah sukun ketika muda berwarna hijau terang dan saat masak berubah menjadi hijau kekuningan. Warna daging buah sukun pada S1, S2, S3, S7, S8, dan S9 memilki warna putih, sedangkan pada S4, S5, dan S6 memiliki warna kuning muda. Menurut Harmanto (2012), daging buah sukun memiliki tekstur kompak, berserat halus, rasa agak manis, dan beraroma spesifik.

Banyaknya buah per tanaman sukun pada S1, S2, S3, dan S5 termasuk dalam kategori banyak, pada S4, S6, S7 dan S9 termasuk kategori sedang, dan pada S8 termasuk kategori sedikit. Menurut Sunarjono (2008), tanaman sukun sudah mulai berbuah pada umur 3-4 tahun. Buah sukun dapat dipanen apabila sudah 
masak, yaitu setelah berumur 3 bulan. Hasil buah sukun 200-700 buah per pohon per tahun. Suprapti (2006) menyatakan bahwa umumnya panen raya dilakukan pada bulan Januari-Februari, sedangkan panen susulan dilakukan pada bulan Juli-Agustus. Bulan-bulan diluar masa panen tersebut sukun masih tetap berbuah, akan tetapi dalam jumlah yang relatif sedikit.

\section{Identifikasi karakter morfologi keseluruhan}

Hasil pengukuran kemiripan seluruh karakter morfologi disajikan pada Tabel 1.

Tabel 1 Matriks koefisien kemiripan seluruh karakter morfologi

\begin{tabular}{lccccccccc}
\hline & S1 & S2 & S3 & S4 & S5 & S6 & S7 & S8 & S9 \\
\hline S1 & 1,00 & & & & & & & & \\
S2 & 0,94 & 1,00 & & & & & & & \\
S3 & 0,91 & $\mathbf{0 , 9 7}$ & 1,00 & & & & & & \\
S4 & 0,73 & 0,79 & 0,82 & 1,00 & & & & & \\
S5 & 0,94 & 0,88 & 0,85 & 0,76 & 1,00 & & & & \\
S6 & 0,82 & 0,82 & 0,79 & 0,88 & 0,85 & 1,00 & & \\
S7 & 0,85 & 0,91 & 0,94 & 0,82 & 0,79 & 0,79 & 1,00 & & \\
S8 & 0,91 & 0,85 & 0,82 & $\mathbf{0 , 7 0}$ & 0,88 & 0,79 & 0,85 & 1,00 & \\
S9 & 0,85 & 0,91 & 0,88 & 0,79 & 0,85 & 0,82 & 0,94 & 0,88 & 1,00 \\
\hline
\end{tabular}

Berdasarkan Tabel 1 matriks koefisien kemiripan seluruh karakter morfologi pada sukun menunjukkan nilai tertinggi pada S2 dengan S3 sebesar 0,97 dengan karakter pembeda yaitu lebar daun. Nilai terendah terdapat pada S4 dengan S8 sebesar 0,70 dengan karakter pembeda yaitu bentuk tajuk, pola percabangan, jumlah cabang utama, arah pertumbuhan, panjang daun, lebar daun, panjang bunga jantan, bentuk buah, warna daging buah, dan banyaknya buah per tanaman. Identifikasi pengelompokan sembilan tanaman sukun berdasarkan karakter morfologi keseluruhan dianalisis melalui metode SAHN dengan pengelompokkan sampel sukun menggunakan metode UPGMA. Hasil dari analisis berbentuk dendrogram dan disajikan pada Gambar 5.

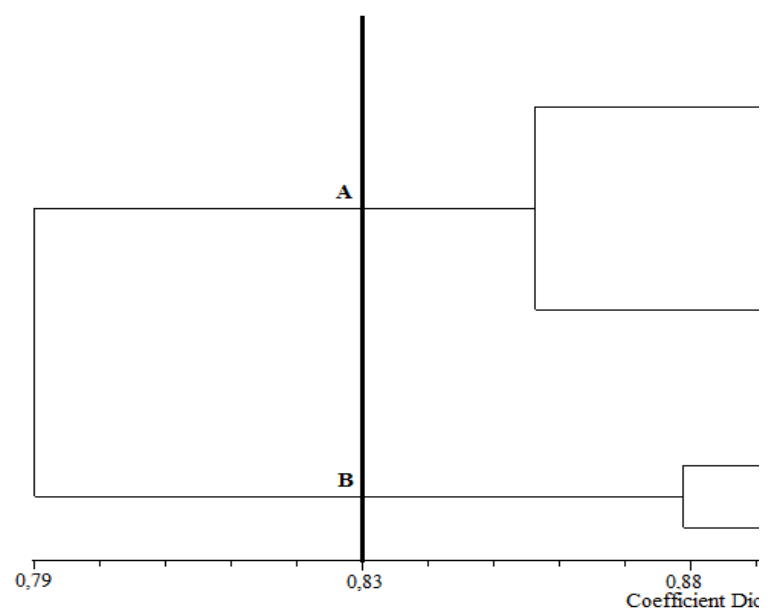

Gambar 5 Dendrogram pengelompokan 9 tanaman sukun berdasarkan karakter morfologi keseluruhan

Berdasarkan Gambar 5 hasil dendrogram morfologi keseluruhan tanaman sukun menunjukkan nilai koefisian kemiripan tertinggi sebesar 0,97 atau $97 \%$ (nilai koefisian ketidakmiripan 3\%) pada S2 dengan S3. Nilai koefisian kemiripan terendah sebesar 0,70 atau $70 \%$ (nilai koefisien ketidakmiripan $30 \%$ ) pada S4 dengan S8. Cahyarini et al. (2004) menyatakan bahwa jarak kemiripan dapat dikatakan jauh apabila kurang dari 0,60 atau $60 \%$. Nilai koefisien kemiripan 0,83 atau 83\% (nilai koefisien ketidakmiripan 17\%) dibedakan menjadi dua kelompok yaitu $A$ dan $B$.

Kelompok A terdiri dari tujuh tanaman yaitu $\mathrm{S} 1, \mathrm{~S} 2$, S3, S5, S7, S8 dan S9. S2 dengan S3 memiliki nilai koefisien kemiripan tertinggi sebesar 0,97 dengan karakter pembeda pada lebar daun. S1 dengan S5 memiliki nilai koefisien kemiripan sebesar 0,94 dengan karakter pembeda pada bentuk tajuk dan warna daging buah. S7 dengan S9 memiliki nilai koefisien kemiripan sebesar 0,94 dengan karakter pembeda pada bentuk tajuk dan lebar daun. Kelompok B terdiri dari dua tanaman yaitu S4 dan S6 memiliki nilai koefisien kemiripan sebesar 0,88 dengan karakter pembeda pada pola percabangan, arah pertumbuhan, lebar daun, dan panjang bunga jantan.

Keragaman karakter morfologi tanaman umumnya muncul pada sifat kuantitatif, keseragaman karakter cenderung muncul pada sifat kualitatif. Menurut Syukur et al. (2012), sifat kuantitatif banyak dipengaruhi oleh faktor lingkungan, sedangkan sifat kualitatif sedikit/tidak dipengaruhi faktor lingkungan. Morfologi suatu tanaman ditentukan oleh faktor genetik, lingkungan, dan interaksi antara keduanya. Faktor genetik berasal dari sifat tetuanya yang diwariskan kepada keturunannya, sedangkan faktor lingkungan yaitu cahaya, suhu, 
kelembaban, curah hujan, kondisi tanah, dan ketinggian tempat. Trimanto (2012) menyatakan bahwa tanaman sejenis yang ditanam pada lingkungan yang berbeda cenderung beradaptasi dengan lingkungan setempat.

Hasil dendrogram karakter morfologi keseluruhan tanaman sukun menunjukkan bahwa setiap sampel membentuk satu kelompok berdasarkan atas banyaknya kesamaan karakter yang dimiliki, baik dalam kabupaten yang sama maupun kabupaten yang berbeda. Miswarti et al. (2017) menyatakan bahwa semakin banyak kesamaan karakter yang dimiliki maka nilai keragamannya rendah. Sebaliknya semakin sedikit kesamaan karakter yang dimiliki maka nilai keragamannya tinggi.

\section{KESIMPULAN DAN SARAN}

\section{Kesimpulan}

1. Tanaman sukun memiliki tinggi 16,79-17,90 m, lingkar batang 108-168 cm, diameter tajuk 6,14-8,86 $\mathrm{m}$, bentuk tajuk piramida, piramida luas, bulat panjang, tidak teratur, pola percabangan tegak, berlawanan, tidak teratur, arah pertumbuhan tegak dan condong ke atas. Panjang daun 42,2-78,6 cm, lebar daun 30,2-59,2 cm, panjang tangkai daun 5,0 $8,2 \mathrm{~cm}$, bentuk daun bulat telur, pangkal membaji, ujung meruncing, bertulang menyirip, warna daun hijau tua, dan permukaan daun mengkilap. Panjang bunga jantan 9,0-13,4 cm, diameter bunga jantan 1,7-3,0 cm, bentuk bunga betina bulat, bentuk bunga jantan jorong, warna bunga betina hijau muda, warna bunga jantan hijau muda ketika muda, kuning tua ketika masak, dan cokelat ketika tua. Panjang buah 12,2-19,0 cm, diameter buah 12,8$16,4 \mathrm{~cm}$, panjang tangkai buah $5,8-8,2 \mathrm{~cm}$, berat 0,79-1,77 kg, bentuk buah bulat dan bujur, pangkal menjorok, ujung cembung, warna kulit hijau kekuningan, warna daging putih dan kuning muda, banyaknya buah per tanaman sedikit, sedang, dan banyak.

2. Keragaman morfologi tanaman sukun yaitu 3-30\%.

\section{Saran}

Saran yang dapat diberikan yaitu untuk memperkuat hasil analisis karakter morfologi perlu dilanjutkan dengan analisis molekuler atau analisis sitologi.

\section{DAFTAR PUSTAKA}

Adinugraha HA, Kartikawati NK. 2012. Variasi morfologi dan kandungan gizi buah sukun. Wana Benih 13(2): 99-106.

Akanbi TO, Nazamid S, Adebowale AA. 2009. Functional and pasting properties of a tropical breadfruit (Artocarpus altilis) starch from lle-lfe, Osun State, Nigeria. International Food Research J 16: 151-157.

Alercia A. 2011. Key characterization and evaluation descriptors: methodologies for the assessment of 22 crops. Rome: Bioversity International.

Apriani HD, Sumono, Panggabean S. 2015. Kajian kinerja irigasi tetes pada tanah latosol dengan budidaya tanaman caisim (Brassica juncea L.). J Rekayasa Pangan dan Pertanian 3(1): 109-116.

Azmi A, Yuwono AS, Erizal, Kurniawan A, Mulyanto B. 2015. Analysis of dustfall generation from regosol soil in Java Island, Indonesia. ARPN Journal of Engineering and Applied Sciences 10(8): 81848191.

Bioversity. 2007. Descriptors for durian (Durio zibethinus Murr.). Rome: Bioversity International.

Cahyarini RD, Yunus A, Purwanto E. 2004. Identifikasi keragaman genetik beberapa varietas lokal kedelai di Jawa berdasarkan analisis isozim. Agrosains 6 (2): 96-104.

Deivanai S, Bhore SJ. 2010. Breadfruit (Artocarpus altilis Fosb.)-an underutilized and neglected fruit plant species. Middle-East $\mathrm{J}$ of Scientific Research 6(5): 418-428.

Djafaar TF. 2004. Sukun cilacap yang lebih menguntungkan. Tabloid Sinar Tani. BPTP Yogyakarta.

Elevitch CR. 2006. Traditional trees of pacific islands: their culture, environment, and use. Hawaii: Permanent Agricalture Resource, Holualoa.

Harmanto N. 2012. Daun sukun, si daun ajaib penakluk aneka penyakit. Jakarta: Agromedia Pustaka.

Hendalastuti H, Rojidin A. 2006. Karakteristik budidaya dan pengolahan buah sukun: studi kasus di Solok dan Kampar. Prosiding seminar hasil litbang hasil hutan, p 220-232.

IPGRI. 2000. Descriptors for jackfruit (Artocarpus heterophyllus). Rome: International Plant Genetic Resources Institute.

Jones AMP, Murch SJ, Ragone D, Tavana NG, Bernotas DW. 2011. Beyond the bounty: breadfruit (Artocarpus altilis) for food security and novel foods in the 21st century. J Ethnobotany 9(1): 130-152.

Mansyurdin, Maideliza T, Chairul, Susiana E. 2016. Studi lingkar tumbuh pohon di Kawasan Hutan Taman Nasional Siberut Kepulauan Mentawai. J Metamorfosa 3(1): 8-14.

Mawazin, Suhaendi H. 2008. Pengaruh jarak tanam terhadap pertumbuhan diameter Shorea parvifolia Dyer. J Penelitian Hutan dan Konservasi Alam 5(4): 381-388.

Miswarti, Putra WE, Sugandi D. 2017. Analisis keragaman plasma nutfah durian di Provinsi Bengkulu berdasarkan karakter morfologi. Bul Plasma Nutfah 23(1): 59-68.

Moles AT, Warton DI, Warman L, Swenson NG, Laffan SW, Zanne AE, Pitman A, Hemmings FA, Leishman MR. 2009. Global patterns in plant height. $J$ of Ecology 97(5): 923-932.

Nayeem N, Sushmita. 2013. Artocarpus altilis: over view of a plant which is referred to as bread fruit. International Journal of Pharmaceutical Sciences Letters 3(5): 273-276.

Nochera CL, Ragone D. 2016. Preparation of a breadfruit flour bar. J Foods Sci 5(2): 37. 
Purwantoyo E. 2007. Budidaya dan pascapanen sukun. Semarang: Aneka IImu.

Ragone D. 1997. Breadfruit. Artocarpus altilis (Parkinson) Fosberg. promoting the conservation and use of underutilized and neglected crops. Italy: 10 Institute of Plant Genetics and Crop Plant Research, Gatersleben/International Plant Genetic Resources Institute, Rome.

Rehatta H, Kesaulya H. 2010. Identifikasi tanaman sukun (Artocarpus communis Forst) di Pulau Ambon. J Budidaya Pertanian 6(2): 58-62.

Rukmana R. 2007. Untung berlipat dari budidaya sukun tanaman multi manfaat. Yogyakarta: Lily Publisher.

Sikarwar MS, Hiu BJ, Subramaniam K, Valeisamy BD, Yean KL, Balaji K. 2014. A review on Artocarpus altilis (Parkinson) Fosberg (breadfruit). $\mathrm{J}$ of Applied Pharmaceutical Science 4(8): 91-97.
Suprapti ML. 2006. Tepung sukun: pembuatan dan pemanfaatannya. Yogyakarta: Penerbit Kanisius.

Supriyati Y. 2010. Sukun sebagai sumber pangan alternatif substitusi beras. Iptek Tanaman Pangan 5(2): 219-231.

Syukur M, Sujiprihati S, Yunianti R. 2012. Teknik pemuliaan tanaman. Jakarta: Penebar Swadaya.

Trimanto. 2012. Karakterisasi dan jarak kemiripan uwi (Dioscorea alata L.) berdasarkan penanda morfologi umbi. Buletin Kebun Raya 15(1): 47-58.

Yang Q, Lu L, Lou LM, Zhou N. 2015. Simulation research for outline of plant leaf. Advances in Image and Graphics Technologies. 10th Chinese Conference IGTA, Beijing-Cina Proceedings, p 375385. 